\title{
Hypoglycemia Prevention Practice and Associated Factors Among Patients with Diabetes Mellitus Following at Public Hospitals of Central Zone, Tigray, Ethiopia, 2018
}

Gebrewahd Bezabh Gebremichael ( $\sim$ Neverimpossible12@yahoo.com )

Mekelle University College of Health Sciences https://orcid.org/0000-0001-7374-595X

Teklewoini Mariye Zemichael

Axum University

Research article

Keywords: practice, hypoglycemia, prevention, diabetes mellitus, Ethiopia.

Posted Date: July 19th, 2019

DOI: https://doi.org/10.21203/rs.2.11704/v1

License: (c) (1) This work is licensed under a Creative Commons Attribution 4.0 International License.

Read Full License 


\section{Abstract}

Background Hypoglycemia is an acute medical situation that occurs when blood sugar falls below the recommended level. Even though, hypoglycemia prevention practice in the management of diabetes mellitus is one cornerstone in controlling the effect of hypoglycemia, hypoglycemia prevention practice among patients with diabetes mellitus is insufficiently studied. Moreover, the existed scarce literature in Ethiopia revealed hypoglycemia prevention practice is inadequate. Thus, this study tried to assess hypoglycemia prevention practices and associated factors among diabetic patients. Methods Hospitalbased, cross-sectional study design was employed from April one to March one 2018 in Central Zone of Tigray Regional state of Ethiopia. A total of 272 diabetes mellitus patients were selected by systematic random sampling method from study area. The collected data was checked for its completeness and then entered into Epi data version 3.1 then cleaned and analyzed using SPSS version 23. Binary logistic regression model $(\mathrm{AOR}, 95 \% \mathrm{Cl}$ and $\mathrm{p}$-value $<0.05)$ was used to determine the predictors of hypoglycemia prevention practice. Results the mean age of respondents was 52.19 years and about $100(63.2 \%)$ had good hypoglycemia prevention practice. Knowledge regarding hypoglycemia [AOR $=10.34 ; 95 \% \mathrm{Cl}[5.41$, 19.89]], having a glucometer at home [AOR=3. $02 ; 95 \% \mathrm{Cl}[1.12,8.12]]$, attitude regarding diabetes mellitus $[A O R=2.36 \mathrm{Cl}[1.26,4.39]]$, being governmental employee [AOR=5. 19, 95\% $\mathrm{Cl}[1.63,16.58]]$ and being divorced $[A O R=0.13,95 \% \mathrm{Cl}[0.32,0.53]]$ were found significantly associated with good hypoglycemia prevention practice. Conclusion Around two third of the study participants were found to have good hypoglycemia prevention practice. Good knowledge and favorable attitude toward diabetes mellitus, having glucometer at home, being governmental employee and divorced were found to be the predictors of good hypoglycemia prevention practice.

\section{Abstract}

Background: Hypoglycemia is an acute medical situation that occurs when blood sugar falls below the recommended level. Even though, hypoglycemia prevention practice in the management of diabetes mellitus is one cornerstone in controlling the effect of hypoglycemia, hypoglycemia prevention practice among patients with diabetes mellitus is insufficiently studied. Moreover, the existed scarce literature in Ethiopia revealed hypoglycemia prevention practice is inadequate. Thus, this study tried to assess hypoglycemia prevention practices and associated factors among diabetic patients.

Methods: Hospital-based, cross-sectional study design was employed from April one to March one 2018 in Central Zone of Tigray Regional state of Ethiopia. A total of 272 diabetes mellitus patients were selected by systematic random sampling method from study area. The collected data was checked for its completeness and then entered into Epi data version 3.1 then cleaned and analyzed using SPSS version 23. Binary logistic regression model ( $A O R, 95 \% \mathrm{Cl}$ and $p$-value $<0.05)$ was used to determine the predictors of hypoglycemia prevention practice.

Results: the mean age of respondents was 52.19 years and about 100 (63.2\%) had good hypoglycemia prevention practice. Knowledge regarding hypoglycemia [AOR $=10.34 ; 95 \% \mathrm{Cl}[5.41,19.89]]$, having a 
glucometer at home $[A O R=3.02 ; 95 \% \mathrm{Cl}[1.12,8.12]]$, attitude regarding diabetes mellitus [AOR $=2.36 \mathrm{Cl}$ $[1.26,4.39]]$, being governmental employee $[\mathrm{AOR}=5.19,95 \% \mathrm{Cl}[1.63,16.58]]$ and being divorced [AOR = $0.13,95 \% \mathrm{Cl}[0.32,0.53]]$ were found significantly associated with good hypoglycemia prevention practice.

Conclusion: Around two third of the study participants were found to have good hypoglycemia prevention practice. Good knowledge and favorable attitude toward diabetes mellitus, having glucometer at home, being governmental employee and divorced were found to be the predictors of good hypoglycemia prevention practice.

Keywords: practice, hypoglycemia, prevention, diabetes mellitus, Ethiopia.

\section{Background}

Hypoglycemia, defined as a blood glucose level $<70 \mathrm{mg} / \mathrm{dL}(3.9 \mathrm{mmol} / \mathrm{L})$ is an acute complication of diabetes mellitus $(1,2)$. Hypoglycemia is the most common and highly feared adverse effect of diabetes mellitus therapy, particularly patients with insulin therapy (3). Although there is a lack of real-world data on hypoglycemia, a recent analysis of the existing literature has shown that hypoglycemia is more common in clinical practice (4).

In addition to causing distress for patients, severe hypoglycemia is associated with cardiac arrhythmias, cardiac ischemia, seizures, brain damage, and death (5-7). In type 2 diabetes, one longitudinal cohort study in elderly patients revealed that severe hypoglycemia episodes are associated with an increased risk of dementia (7). Other similar study also found that severe hypoglycemia causes brain damage (8). An estimated $2-4 \%$ of people with type 1 diabetes mellitus die from hypoglycemia each year (9)

It is an important concern for patients with diabetes mellitus who are treated with insulin, and also for health care providers who need to consider a patient's risk of hypoglycemia when maintaining or adjusting insulin doses to individualized glycemic targets. Consequently, clinical decisions on glycemic control are often made according to the relative benefits of insulin therapy versus the risk of hypoglycemia (10).

Sub-Saharan Africa is facing inadequate skilled staff and lack of resources to manage diabetes mellitus problem. This is a major challenge for many sub-Saharan countries with the prevalence of diabetes mellitus complications (11-14). Hypoglycemia is a significant contributor to total diabetes mellitus expenditure. The health economic burden associated with hypoglycemia can be related with extensive economic loss in diabetes mellitus patients with their family, to health systems and to the national economies through direct and indirect costs (15-19).

As a result of a lack of comprehensive data particularly in developing countries, the economic impact of hypoglycemia on patients and healthcare providers has been remained poorly understood, causing a need for additional studies to support the cost-effectiveness of future treatment strategies in the clinical 
setting. Besides, hypoglycemia has shown negative impact on quality of life and productivity in the workplace (19-21).

However, through identifying the associated factors with prevention practices of hypoglycemia such as optimization of insulin treatment, better patient education or improved access to blood glucose testing, developing good knowledge on hypoglycemia and promoting favorable attitude towards diabetes mellitus may help patients more effectively to meet their treatment goals. Alleviating some of the costly impacts of hypoglycemia on people with diabetes mellitus can delay the onset and reduce the development of complication that leads to a prolonged hospitalization and reduced quality of life (22-24).

Moreover, enforcement of hypoglycemia prevention practice in the management of diabetes mellitus was recognized to be useful and effective. However, findings of previous studies in Amhara region of Ethiopia indicated that hypoglycemia prevention practice was low $(25,26)$.

Even though a number of articles have been held on self-care practice locally and internationally, hypoglycemia prevention practice among patients with diabetes mellitus is insufficiently studied in Tigray region particularly in the study area. So, this study has tried to assess hypoglycemia prevention practices and associated factors among patients with diabetes mellitus in public Hospitals of Central Zone of Tigray, Ethiopia.

\section{Methods}

\section{Study area and period}

The study was conducted in four public hospitals (Aksum University Referral Hospital, Saint Marry Hospital, Adwa Hospital, and Abyi-adi Hospital) of the central zone, from April one to March one 2018.

\section{Study design}

A hospital-based cross-sectional study design was carried out among diabetes mellitus patients.

\section{Population}

The Source population was all diabetic mellitus patients who visit the general public Hospitals of the central zone of Tigray during the data collection period and the Study population was all selected diabetes mellitus patients who visit general public Hospitals of the Central zone of Tigray, Ethiopia.

\section{Sample size determination}

Sample size was determined using single population proportion formula using EPI Info software version 7.1.1. Confidence level, $95 \%$, marginal error (d) $5 \%$ and prevalence was taken from a study conducted in 
South Gondar, Northwest, and Ethiopia in 2015 which was $21.4 \%$ of good practice in hypoglycemia prevention (25). By adding 5\% non-response rate the final size was 272 .

\section{Sampling procedure and techniques}

The sample size was proportionally distributed into each hospital. Then, individual participants were selected using simple random sampling technique.

\section{Data collection tool and technique}

The data collection tool was adapted from similar literatures $(25,27,28)$. Data was collected through face to face interview using the structured questionnaire by four B.Sc. nurses with two supervisors.

\section{Data quality assurance}

The questionnaire was initially prepared in English, then translated into the local language (Tigrigna) by an individual who has a good ability of the two languages, then translated back to English by the different person to ensure consistency. Two days training was given for data collectors and supervisors. A week prior to the actual data collection period, the questionnaire was pre-tested on $5 \%$ of the total sample size outside the study area. The collected data were checked manually at the spot and cleaned in the SPSS for its completeness.

\section{Data processing and analysis}

Data was coded and entered into Epi-Data version 3.1 and then it was exported to SPSS version 22.0 for further analysis. Binary logistic regression model was used to identify the predictors of hypoglycemia prevention practice. Variables which were potential independent predictors on bi-variate analysis with Pvalue $\leq 0.2$ were entered to multivariable logistic regression analysis. Finally, the magnitude of association between the dependent and independent variables was measured using odds ratios AOR with $95 \%$ confidence interval and statistical significance was declared at P-Value $<0.05$.

\section{Operational definitions}

Good practice; participants who scored mean and above from the hypoglycemia prevention practice questions

Poor practice; participants who scored below the mean value from the hypoglycemia prevention practice questions (25). 


\section{Ethical consideration}

Ethical clearance was obtained from the Institutional Review Board of Aksum University, college of health science. Permission was obtained from the medical directors of the respective public hospitals. Verbal consent was obtained from each of the study participants. Respondents were allowed to refuse or discontinue participation at any time they want. Information was recorded anonymously. Confidentiality and privacy were ensured throughout the study.

\section{Results}

\section{Socio-Demographic Profile of the Study Participants:}

A total of 272 diabetes mellitus patients were included in the study with a response rate of $100 \%$. The mean age of the respondents was 43.62 with S.D of \pm 17.07 years. Of the total respondents, one hundred forty-three 143 (52.6\%) were males. One hundred seventy-three (63.6\%) of them were urban residents. One hundred thirty-eight 138 (50.8\%) participants did not had a formal education; two hundred sixteen (79.4\%) respondents were Orthodox Christian followers and 254 (93.4\%) were Tegaru. Two hundred twenty-eight $228(83.7 \%)$ of the respondents were unemployed. One hundred fifty-seven $(57.7 \%)$ of respondents were married (Table1).

Health profile, Knowledge and Attitude of the study participants:

The mean duration of the participants was $4.61(95 \% \mathrm{Cl})$ with a minimum of one year and a maximum of 25 years. Of the total respondents one hundred-thirteen (41.5\%) were medically confirmed type one diabetes mellitus. Forty three (15.8\%) participants had a family history of diabetes mellitus and 49 (18\%) respondents had a glucometer at home. One hundred seventy-nine respondents (65.8\%) attended diabetic education. Seventy-seven of the total respondents (28.3\%) had medically confirmed long-term diabetes mellitus complication. One hundred fifty-eight of the total respondents (58.2\%) had known their glucose level. From the total respondent only fifty-seven (21\%) were a member of the diabetic association, but 95 (34.9\%) of them did not know there is diabetes mellitus association. One hundred forty-three 143 (52.6\%) had good knowledge regarding hypoglycemia and 96 (35.3\%) had a favorable attitude regarding diabetes mellitus (Table-2).

\section{Hypoglycemia prevention practice and associated factors}

Nearly-three fourth, $63.2 \%$ [95\% Cl; $58.6,68.8]$ of participants had good hypoglycemia prevention practice.

In the multivariable logistic regression analysis, only five variables had shown statistically significant association with good hypoglycemia prevention practice.

Good knowledge regarding hypoglycemia was positively statically associated with Good hypoglycemia prevention practice. The odds of having Good knowledge was 10.34 [AOR=10.34; 95\% $\mathrm{Cl}[5.41,19.89]$ ] 
times more strongly associated with good hypoglycemia prevention practice.

Having a glucometer at home showed a significant association with Good hypoglycemia prevention practice. Participants who had glucometer at their home were found three (AOR $=3.02 ; 95 \% \mathrm{Cl} ; 1.12$ 8.12) times higher more likely to have good hypoglycemia prevention practice than their counterparts.

Those who had favorable attitudes toward diabetes mellitus had more significant hypoglycemia prevention practice than participants who had unfavorable attitude. The odds of having favorable attitudes towards diabetic mellitus were $2.36[\mathrm{AOR}=2.36 \mathrm{Cl}[1.26,4.39]]$ more associated with the prevention of hypoglycemia than to their opposite part.

Being government employee had a significant association with the prevention of hypoglycemia. Governments employees were found 5.19 times higher more likely to have good hypoglycemia prevention practice than farmers $[\mathrm{AOR}=5.19,95 \% \mathrm{Cl}[1.63,16.58]]$.

Being divorced had negative statistical association with good hypoglycemia prevention practice. Those who were divorced had less likely associated with the outcome variability by $87 \%$ than those single participants $[\mathrm{AOR}=0.13,95 \% \mathrm{Cl}[0.32,0.53]]$ (See Table-3).

\section{Discussion}

The study provided an insight into the level of Good practice on the prevention of hypoglycemia and associated factors among patients with diabetes mellitus in public hospitals of Central Zone, Tigray Regional state, Ethiopia, 2018.

The magnitude of good hypoglycemia prevention practice among diabetes mellitus was found $63.2 \%$ $[58.6,68.8]$. This level is considerably higher than the finding documented in South Gondar, Northwest Ethiopia which was $21.4 \%$ (25). This discrepancy could be due to sample size difference, educational status differences and lack of awareness on the importance of hypoglycemia prevention practice.

Good knowledge on hypoglycemia significantly associated with good hypoglycemia prevention practice. The odds of knowledge on prevention of hypoglycemia were 10.34 times strongly associated with the outcome variable $[A O R=10.34 ; 95 \% \mathrm{Cl}[5.41,19.89]$. This finding was supported by the study finding conducted in Benishangul Gomez Regional State Public hospital, Nekemte hospital and Addis Ababa hospital (29-31). This association could reflect, good knowledge can enable participants how to prevent hypoglycemia and thus promotes patients' practical prevention of hypoglycemia.

Having glucometer at home had statistically significant association with good hypoglycemia prevention practice. Comparable finding was also found in a studies conducted in public Hospitals of Central Zone, Tigray (32), Mekelle and Ayder referral hospital (33), Benishangul Gomez Regional State Public Hospitals (29), Addis Ababa in (34). This might be due to having glucometer at home could reinforce patients to measure blood glucose level and apply recommend treatment changes immediately. Moreover regular blood glucose level measurement might lead to lifestyle change that prevents hypoglycemia. 
This study revealed that, favorable attitude towards diabetes mellitus was found statistically associated with good hypoglycemia prevention practice. Participants who had favorable attitude towards diabetes mellitus were 2.36 times more likely to have Good practice in the prevention of hypoglycemia than to their counterparts. Comparable finding was obtained in the studies done in public Hospital of Central Zone Tigray (32), Dilla University Referral Hospital (35), Nekemti Hospital (30) and Nigeria (36). This might be due to having favorable attitude towards acute/chronic diseases like diabetes mellitus is usually shown as an essential factor in practicing an essential health behavior that prevents the overall burden and complications of the health problem such as the hypoglycemia in diabetes mellitus.

This study showed that, government employees were found 5.19 times more likely to engage in good hypoglycemia prevention practice compared to farmers. This study finding is backed by the study conducted in the Nekemte referral Hospital in 2014 (37). This similarity might be because of the educational status of the government employed participants are prone to media that leads to favorable attitude and good knowledge about hypoglycemia.

Participants who are divorced were found $87 \%$ less likely to have good hypoglycemia prevention practice $[\mathrm{AOR}=0.13,95 \% \mathrm{Cl}[0.32,0.53]$. this could be defined by the experience of separation or divorce confers risk for poor health outcomes, including a $23 \%$ higher mortality rate (38).

\section{Conclusion}

Around two third of the study participants were found to be good practice on prevention of hypoglycemia. Good knowledge and favorable attitude of diabetes mellitus, having glucometer at home, governmental employee and divorce of the study participants were found to be the predictors of good practice on prevention of hypoglycemia.

Therefore, health care personnel and Ethiopian diabetic association should focus on patient's awareness, knowledge regarding diabetes mellitus by strengthening information, education and communication program. Generally, burden of the diabetes mellitus complication may be addressed through strengthen skill of staff and self-care practice of the patients.

\section{List Of Abbreviations}

AOR: Adjusted Odds Ratio,

COR: Crude Odds Ratio.

DM: Diabetes Mellitus

FBS: Fasting Blood Sugar

IEC: Information Education and Communication 
IRB: Institutional Review Board

MMS: Modified Morse Scale

SMBG: Self-Monitoring Blood Glucose

\section{Declaration}

\section{Ethics approval and consent to participate}

Ethical clearance was obtained from the Institutional Review Board of Aksum University, college of health sciences; Permission was obtained from the medical directors of the respective public hospitals to conduct the study. Verbal consent was obtained from each of the study participants. Respondents were allowed to refuse or discontinue participation at any time they want. Study participants were identified using codes and unauthorized persons were not having access to the collected data.

Consent to Publish: Not applicable

\section{Availability of Data and Materials}

The data sets used and analyzed during the current study could be made available on reasonable request to corresponding author.

\section{Competing Interests}

This manuscript maintains no competing financial interest declaration from any person or organization, or non-financial competing interests such as political, personal, religious, ideological, academic, intellectual, commercial or any other.

\section{Funding:}

No funding source was received

\section{Authors' Contributions:}

All authors (TM, GB) participated in questionnaire design, data collection, data analysis and manuscript writing and also were involved in the interpretation of the data and contributed to manuscript preparation. Similarly, all authors have read and approved the final version of the manuscript. 


\section{Acknowledgment}

We would like to thank all study participants and data collectors for their contribution in the success of our work.

\section{References}

1. Moghissi ES, Korytkowski MT, DiNardo M, Einhorn D, Hellman R, Hirsch IB, et al. American Association of Clinical Endocrinologists and American Diabetes Association consensus statement on inpatient glycemic control. Diabetes care. 2009;32(6):1119-31. 2. Handelsman Y, Bloomgarden ZT, Grunberger G, Umpierrez G, Zimmerman RS, Bailey TS, et al. American Association of Clinical Endocrinologists and American College of Endocrinology-clinical practice guidelines for developing a diabetes mellitus comprehensive care plan-2015. Endocrine Practice. 2015;21(s1):1-87. 3. Group UHS. Risk of hypoglycaemia in types 1 and 2 diabetes: effects of treatment modalities and their duration. Diabetologia. 2007;50(6):1140-7. 4. Elliott L, Fidler C, Ditchfield A, Stissing T. Hypoglycemia event rates: a comparison between real-world data and randomized controlled trial populations in insulin-treated diabetes. Diabetes Therapy. 2016;7(1):45-60. 5. Frier BM, Schernthaner G, Heller SR. Hypoglycemia and cardiovascular risks. Diabetes care. 2011;34(Supplement 2):S132-S7. 6. Cryer PE. Severe hypoglycemia predicts mortality in diabetes. Diabetes Care. 2012;35(9):1814-6. 7. Badawi O, Waite MD, Fuhrman SA, Zuckerman $\mathrm{IH}$. Association between intensive care unit-acquired dysglycemia and in-hospital mortality. Critical care medicine. 2012;40(12):3180-8. 8. Bree AJ, Puente EC, Daphna-lken D, Fisher SJ. Diabetes increases brain damage caused by severe hypoglycemia. American Journal of Physiology-Endocrinology and Metabolism. 2009;297(1):E194-E201. 9. Cryer PE, Axelrod L, Grossman AB, Heller SR, Montori VM, Seaquist ER, et al. Evaluation and management of adult hypoglycemic disorders: an Endocrine Society Clinical Practice Guideline. The Journal of Clinical Endocrinology \& Metabolism. 2009;94(3):709-28. 10. Munro N, Barnett A. Incidence, worry and discussion about dosing irregularities and self-treated hypoglycaemia amongst HCP s and patients with type 2 diabetes: results from the UK cohort of the Global Attitudes of Patient and Physicians (GAPP 2) survey. International journal of clinical practice. 2014;68(6):692-9. 11. Park PH, Wambui CK, Atieno S, Egger JR, Misoi L, Nyabundi JS, et al. Improving diabetes management and cardiovascular risk factors through peer-led self-management support groups in Western Kenya. Diabetes care. 2015;38(8):e110-e1. 12. Mbanya JCN, Motala AA, Sobngwi E, Assah FK, Enoru ST. Diabetes in sub-saharan africa. The lancet. 2010;375(9733):2254-66. 13. Hall V, Thomsen RW, Henriksen O, Lohse N. Diabetes in Sub Saharan Africa 1999-2011: epidemiology and public health implications. A systematic review. BMC public health. 2011;11(1):564. 14. Beran D, Yudkin JS. Diabetes care in sub-Saharan Africa. The Lancet. 2006;368(9548):1689-95. 15. Hammer M, Lammert M, Mejías SM, Kern W, Frier BM. Costs of managing severe hypoglycaemia in three European countries. Journal of medical economics. 2009;12(4):281-90. 16. Hex N, Bartlett C, Wright D, Taylor M, Varley D. Estimating the current and future costs of Type 1 and Type 2 diabetes in the UK, including direct health costs and indirect societal and productivity costs. Diabetic Medicine. 2012;29(7):855-62. 17. Leese GP, Wang J, Broomhall J, Kelly P, Marsden A, Morrison W, et al. Frequency of severe hypoglycemia requiring 
emergency treatment in type 1 and type 2 diabetes: a population-based study of health service resource use. Diabetes care. 2003;26(4):1176-80. 18. McEwan P, Thorsted BL, Wolden M, Jacobsen J, Evans M. Healthcare resource implications of hypoglycemia-related hospital admissions and inpatient hypoglycemia: retrospective record-linked cohort studies in England. BMJ Open Diabetes Research and Care. 2015;3(1):e000057. 19. Brod M, Christensen T, Thomsen TL, Bushnell DM. The impact of non-severe hypoglycemic events on work productivity and diabetes management. Value in Health. 2011;14(5):66571. 20. Graveling A, Frier B. Impaired awareness of hypoglycaemia: a review. Diabetes \& metabolism. 2010;36:S64-S74. 21. Davis RE, Morrissey M, Peters JR, Wittrup-Jensen K, Kennedy-Martin T, Currie CJ. Impact of hypoglycaemia on quality of life and productivity in type 1 and type 2 diabetes. Current medical research and opinion. 2005;21(9):1477-83. 22. Loganathan A, John K. Economic burden of diabetes in people living with the disease; a field study. Journal of Diabetology. 2013;4(3):5. 23. Yemane T, Belachew T, Asaminew B, Befekadu O. Type II diabetes mellitus in Jimma Town, southwest Ethiopia. Ethiopian Journal of Health Sciences. 2007;17(2). 24. Feleke Y, Enquselassie F. Cost of hospitalization of diabetic patients admitted at Tikur Anbessa Specialized Hospital, Addis Ababa, Ethiopia. Ethiopian medical journal. 2007;45(3):275-82. 25. Gezie GN, Alemie GA, Ayele TA. Knowledge and practice on prevention of hypoglycemia among diabetic patients in South Gondar, Northwest Ethiopia: Institution based crosssectional study. Age. 2015;18(34):208. 26. Berhe KK, Demissie A, Kahsay AB, Gebru HB. Diabetes self care practices and associated factors among type 2 diabetic patients in Tikur Anbessa specialized hospital, Addis Ababa, Ethiopia-a cross sectional study. International Journal of Pharmaceutical Sciences and Research. 2012;3(11):4219. 27. Ahmed 0, Abdela J, Sisay M. LIFESTYLE MODIFICATION: KNOWLEDGE, ATTITUDE AND PRACTICE AMONG DIABETIC PATIENTS HAVING CHRONIC FOLLOW UP IN HIWOT FANA SPECIALIZED UNIVERSITY HOSPITAL, EASTERN ETHIOPIA. Journal of Pharmaceutical Research. 2016;6(12). 28. Asmamaw A, Asres G, Negese D, Fekadu A, Assefa G. Knowledge and attitude about diabetes mellitus and its associated factors among people in Debre Tabor town, Northwest Ethiopia: cross sectional study. Science. 2015;3(2):199-209. 29. Chali SW, Salih MH, Abate AT. Self-care practice and associated factors among Diabetes Mellitus patients on follow up in Benishangul Gumuz Regional State Public Hospitals, Western Ethiopia: a cross-sectional study. BMC Research Notes. 2018;11(1):833. 30. Ayele K, Tesfa B, Abebe L, Tilahun T, Girma E. Self care behavior among patients with diabetes in Harari, Eastern Ethiopia: the health belief model perspective. PloS one. 2012;7(4):e35515. 31. Mamo M, Demissie M. Self Care Practice and Its Associated Factors Among Diabetic Patients In Addisababa Public Hospitals, Cross Sectional Study. Diabetes Cholest metabol 1: 101. Diabetes Cholest metabol.

2016;1(1):2-5. 32. Mariye T, Tasew H, Teklay G, Gerensea H, Daba W. Magnitude of diabetes self-care practice and associated factors among type two adult diabetic patients following at public Hospitals in central zone, Tigray Region, Ethiopia, 2017. BMC research notes. 2018;11(1):380. 33. Berhe KK, Gebru HB, Kahsay HB, Kahsay AA. Assessment of Self Care Management and its Associated Factors among Type 2 Diabetes Patients in Mekelle Hospital and Ayder Referral Hospitals, Mekelle City, Tigray, Northern Ethiopia, 2012/13. Global Journal of Medical Research. 2017. 34. Mamo M, Demissie M. Self care practice and its associated factors among diabetic patients in addisababa public hospitals, cross sectional study. $J$ Diabetes Cholest Metabol. 2016;1(1):2-5. 35. Addisu Y, Eshete A, Hailu E. Assessment of Diabetic Patient Perception on Diabetic Disease and Self-Care Practice in Dilla University Referral Hospital, South Ethiopia. 
J Metabolic Synd. 2014;3(166):2167-0943.1000166. 36. Adejoh SO. Diabetes knowledge, health belief, and diabetes management among the Igala, Nigeria. Sage Open. 2014;4(2):2158244014539966. 37. Amente T, Belachew T, Hailu E, Berhanu N. Self care practice and its predictors among adults with diabetes mellitus on follow up at Nekemte hospital diabetic clinic, West Ethiopia. World Journal of Medicine and Medical Science [Internet] March. 2014. 38. Sbarra DA. Divorce and health: Current trends and future directions. Psychosomatic medicine. 2015;77(3):227.

\section{Tables}

Table1: Socio demographic profile of the participants on practice in prevention of hypoglycemia among patients with diabetes mellitus at public Hospitals of Central zone, Tigray, Ethiopia 2018

\begin{tabular}{|c|c|c|c|c|}
\hline Variable & Category & Poor practice & Good practice & Total \\
\hline \multirow[t]{2}{*}{ Sex } & Male & $46(16.9 \%)$ & $97(35.7 \%)$ & $143(52.6 \%)$ \\
\hline & Female & $54(19.9 \%)$ & $75(27.6 \%)$ & $129(47.4 \%)$ \\
\hline \multirow[t]{3}{*}{ Age } & $<=34$ & $29(11.2 \%)$ & $47(18.1 \%)$ & $76(29.2 \%)$ \\
\hline & $35-64$ & $56(21.5 \%)$ & $92(35.4 \%)$ & $148(56.9 \%)$ \\
\hline & $>=65$ & $10(3.8 \%)$ & $26(10 \%)$ & $36(13.8 \%)$ \\
\hline \multirow[t]{2}{*}{ Residence } & Urban & $55(20.2 \%)$ & $118(43.4 \%)$ & $173(63.6 \%)$ \\
\hline & Rural & $45(16.5 \%)$ & $54(19.9 \%)$ & $99(36.4 \%)$ \\
\hline \multirow[t]{5}{*}{ Educational status } & Cannot read and write & $25(9.2 \%)$ & $35(12.9 \%)$ & $60(22.1 \%)$ \\
\hline & Can read and write & $20(7.4 \%)$ & $52(19.1 \%)$ & $78(28.7 \%)$ \\
\hline & Primary school & $20(7.4 \%)$ & $24(8.8 \%)$ & $44(16.2 \%)$ \\
\hline & Secondary school & $26(9.6 \%)$ & $52(19.1 \%)$ & $78(28.7 \%)$ \\
\hline & College and above & $15(5.5 \%)$ & $23(8.5 \%)$ & $38(14 \%)$ \\
\hline \multirow[t]{5}{*}{ Occupation } & Housewife & $30(11 \%)$ & $40(14.7 \%)$ & $70(25.7 \%)$ \\
\hline & Daily worker & $13(4.8 \%)$ & $29(10.7 \%)$ & $42(15.4 \%)$ \\
\hline & Self employed & $20(7.4 \%)$ & $44(16.2 \%)$ & $64(23.5 \%)$ \\
\hline & Governmental & $14(5.1 \%)$ & $30(11 \%)$ & $44(16.2 \%)$ \\
\hline & Farmer & $23(8.5 \%)$ & $29(10.7 \%)$ & $52(19.1 \%)$ \\
\hline
\end{tabular}

Table 2: Health profile, knowledge and attitude toward hypoglycemia prevention practice among patients with diabetes mellitus at public Hospitals, Central Zone, Tigray, Ethiopia, 2018. 
$\begin{array}{llll}\text { Variable } & \text { Category } & \begin{array}{l}\text { Poor } \\ \text { practice }\end{array} & \text { Good } \\ \text { practice } & \text { Total }\end{array}$

\begin{tabular}{|c|c|c|c|c|}
\hline \multirow[t]{2}{*}{ Type of DM } & Type one & $42(15.4 \%)$ & $71(26.1 \%)$ & $113(41.5 \%)$ \\
\hline & Type two & $58(21.3 \%)$ & $101(37.1 \%)$ & $159(58.5)$ \\
\hline \multirow[t]{2}{*}{ Co-morbidity } & Yes & $26(9.2 \%)$ & $52(19.1 \%)$ & $77(28.3 \%)$ \\
\hline & No & $75(27.6 \%)$ & $120(44.1 \%)$ & $195(71.7 \%)$ \\
\hline \multirow[t]{2}{*}{ Family history } & Yes & $17(6.3 \%)$ & $26(9.6 \%)$ & $43(15.8 \%)$ \\
\hline & No & $83(30.5 \%)$ & $146(53.7 \%)$ & $229(84.1 \%)$ \\
\hline \multirow[t]{2}{*}{ Attend diabetic education } & Yes & $59(21.7 \%)$ & $120(44.1 \%)$ & $179(65.8 \%)$ \\
\hline & No & $41(15.1 \%)$ & $52(19.1 \%)$ & $93(34.2 \%)$ \\
\hline \multirow[t]{3}{*}{ Member of diabetic association } & Yes & $17(6.3 \%)$ & $40(14.7 \%)$ & $57(21 \%)$ \\
\hline & No & $41(15.1 \%)$ & $79(29 \%)$ & $120(44.1 \%)$ \\
\hline & I did not know & $42(15.4)$ & $53(19.5)$ & $95(34.9)$ \\
\hline \multirow[t]{2}{*}{ Having a glucometer } & Yes & $8(2.9 \%)$ & $41(15.1 \%)$ & $49(18 \%)$ \\
\hline & No & $92(33.8 \%)$ & $131(48.2 \%)$ & $223(82 \%)$ \\
\hline \multirow[t]{2}{*}{ Know their current glucose level } & Yes & $54(19.9 \%)$ & $104(38.2 \%)$ & $158(58.2 \%)$ \\
\hline & No & $46(16.9 \%)$ & $68(25 \%)$ & $114(41.8 \%)$ \\
\hline \multirow[t]{2}{*}{ Attitude toward DM } & Favorable attitude & $36(13.2 \%)$ & $96(35.3 \%)$ & $132(48.5 \%)$ \\
\hline & $\begin{array}{l}\text { Unfavorable } \\
\text { attitude }\end{array}$ & $64(23.5 \%)$ & $76(27.9 \%)$ & $140(51.4 \%)$ \\
\hline \multirow[t]{2}{*}{$\begin{array}{l}\text { Knowledge toward } \\
\text { hypoglycemia }\end{array}$} & Good knowledge & $36(13.2 \%)$ & $143(52.6 \%)$ & $\begin{array}{l}179 \\
(65.8 \%)\end{array}$ \\
\hline & Poor knowledge & $64(23.5 \%)$ & $29(10.7 \%)$ & 93 (33.8\%) \\
\hline
\end{tabular}


Table 3: Bivariate and multivariable logistic regression analysis result of significant variables among patients with diabetes mellitus at public hospitals of central zone of Tigray, Ethiopia in 2018

\begin{tabular}{|c|c|c|c|c|c|}
\hline Variable & Category & $\begin{array}{l}\text { Poor } \\
\text { practice }\end{array}$ & $\begin{array}{l}\text { Good } \\
\text { practice }\end{array}$ & COR & AOR \\
\hline \multirow[t]{4}{*}{ Marital status } & Married & $50(18.4 \%)$ & 107(39.3\%) & $0.94[0.36,2.42]$ & $0.57[0.16,1.96]$ \\
\hline & Divorced & $32(11.8 \%)$ & $32(11.8 \%)$ & $0.44[0.16,1.21]$ & $0.13[0.32,0.53]$ * \\
\hline & Widowed & $11(4 \%)$ & $17(6.3 \%)$ & $0.67[0.21,2.17]$ & $0.34[0.78,1.49]$ \\
\hline & Single & $7(2.6 \%)$ & $16(5.9 \%)$ & 1 & 1 \\
\hline \multirow[t]{5}{*}{ Occupation } & Housewife & $30(11 \%)$ & $40(14.7 \%)$ & $1.05[0.51,2.18]$ & $0.72[0.28,1.78]$ \\
\hline & Daily worker & $13(4.8 \%)$ & $29(10.7 \%)$ & $1.76[0.75,4.15]$ & $0.9[0.31,2.65]$ \\
\hline & Self employed & $20(7.4 \%)$ & $44(16.2 \%)$ & $1.74[0.82,3.73]$ & $1.76[0.69,4.52]$ \\
\hline & Governmental & $14(5.1 \%)$ & $30(11 \%)$ & $1.7[0.73,3.93]$ & $\underset{*}{5.19[1.63,16.58]}$ \\
\hline & Farmer & $23(8.5 \%)$ & $29(10.7 \%)$ & 1 & 1 \\
\hline \multirow{2}{*}{$\begin{array}{l}\text { Diabetic } \\
\text { education }\end{array}$} & Yes & $59(21.7 \%)$ & $120(44.1 \%)$ & $1.6[0.96,2.68]$ & $0.88[0.44,1.75]$ \\
\hline & No & $41(15.1 \%)$ & $52(19.1 \%)$ & 1 & 1 \\
\hline \multirow{2}{*}{$\begin{array}{l}\text { Having } \\
\text { glucometer }\end{array}$} & Yes & $8(2.9 \%)$ & $41(15.1 \%)$ & $3.59[1.61,8.03]$ & $3.02[1.12,8.12]$ * \\
\hline & No & $92(33.8 \%)$ & 131(48.2\%) & 1 & 1 \\
\hline \multirow[t]{2}{*}{$\begin{array}{l}\text { Attitude toward } \\
\text { DM }\end{array}$} & $\begin{array}{l}\text { Favorable } \\
\text { attitude }\end{array}$ & $36(13.2 \%)$ & $96(35.3 \%)$ & $2.25[1.35,3.73]$ & $2.36[1.26,4.39]$ * \\
\hline & $\begin{array}{l}\text { Unfavorable } \\
\text { attitude }\end{array}$ & 64(23.5\%) & 76(27.9\%) & 1 & 1 \\
\hline \multirow{2}{*}{$\begin{array}{l}\text { Knowledge } \\
\text { toward } \\
\text { hypoglycemia }\end{array}$} & $\begin{array}{l}\text { Good } \\
\text { knowledge }\end{array}$ & $36(13.2 \%)$ & 143(52.6\%) & $8.76[4.95,15.52]$ & $\begin{array}{l}10.34[5.41,19.89] \\
\text { * }\end{array}$ \\
\hline & $\begin{array}{l}\text { Poor } \\
\text { knowledge }\end{array}$ & $64(23.5 \%)$ & $29(10.7 \%)$ & 1 & 1 \\
\hline
\end{tabular}

*Shows those variables significantly associated with the outcome variable at $p$ value $<0.05$. 